\title{
EL DEBATE SOBRE LA CREACION DEL MINISTERIO DE SANIDAD EN LA ESPAÑA DEL PRIMER TERCIO DEL SIGLO XX. DISCURSO IDEOLOGICO E INICIATIVAS POLITICAS
}

A Agustín Albarracín

\section{Rafael Huertas}

Desde que las monarquías ilustradas de la segunda mitad del siglo XVIII comenzaron a considerar la salud de sus súbditos como una "razón de Estado» (1), hasta que las modernas constituciones han contemplado, de manera casi unánime, el derecho a la salud de los ciudadanos, sancionando, como en el caso español, que «compete a los poderes públicos organizar y tutelar la salud pública a través de medidas preventivas y de las prestaciones y servicios necesarios» (2), un largo proceso de intervención estatal en materia de salud ha ido configurando - con distintos

Trabajo realizado en el marco del Proyecto de Investigación n. ${ }^{\circ}$ H045/91, subvencionado por el Plan Regional de Investigación de la Comunidad Autónoma de Madrid. 
grados de desarrollo según el país que consideremos- una compleja estructura administrativa con fines higiénicos, médico-sociales y asistenciales.

Históricamente, esta plasmación institucional de la Higiene Pública puede considerarse, en general, como la respuesta de los poderes públicos a dos tipos de problemas. En primer lugar, la amenaza de enfermedades castastróficas, epidémicas, procedentes de otros lugares, obligaron a los gobiernos a instaurar férreos controles de Sanidad, tanto exterior como interior, que redundaron en la organización sanitaria de todo el Estado; un claro ejemplo de ello fue la creación, por el poder borbón español, de la Junta Suprema de Sanidad, ante el peligro de la peste de Marsella de 1720 (3).

En segundo lugar, las crisis económicas del último tercio del siglo XIX motivaron un agravamiento de las ya de por sí penosas condiciones de vida del proletariado, con el aumento de la morbimortalidad de numerosas enfermedades infecciosas y carenciales que se denominaron "sociales" (4) y que motivaron no solo una serie importante de teorizaciones sobre el "círculo vicioso» enfermedad-pobreza (5), sino que obligaron al poder burgués a promover medidas de higiene individual y colectiva tendentes a garantizar una fuerza de trabajo sana, capaz de hacer frente a las crisis, y a detener el avance del movimiento obrero reivindicador de mejoras en las condiciones de vida y de trabajo (6).

En España, una de las consecuencias del escaso desarrollo socioeconómico que caracterizó los años del cambio de siglo fue, sin duda, la muy precaria situación sanitaria del país. La elevada morbimortalidad por enfermedades infecciosas fue denunciada en repetidas ocasiones por nuestros higienistas más ilustres (7), al mismo tiempo que se clamaba por una decidida intervención del gobierno para atajar y mejorar dicha situación de subdesarrollo sanitario (8). En 1913, Manuel Martín Salazar argumentaba que

Basta reflexionar un poco sobre estas cifras tan enormes de nuestra mortalidad anual, para formar idea de la importancia del problema sanitario en España y del deber ineludible que tienen los Gobiernos de acometer con la mayor prontitud la empresa de nuestra regeneración sanitaria. No es de creer que cuando a los hombres públicos que rigen los destinos del país se les plantee esta cuestión en estos términos escuetos, abrumadores, mostrándoles las cifras de nuestra mortalidad por infecciones, y se les convenza de que ese número de vidas que desaparecen cada año son pérdidas debidas en su mayor parte al atraso de nuestra administración sanitaria, resistan el impulso humanitario de poner manos a la obra y aprobar presto en el parlamento una legislación de Sanidad que ponga término a este grave estado de cosas» (9).

Esta preocupación por el mal funcionamiento de la administración sanitaria y por la enorme mortalidad debida a enfermedades infecciosas, llevó a M. Martín Salazar a elaborar en los años veinte, siendo Inspector General de Sanidad, un Proyecto de Ley de Profilaxis de enfermedades evitables que, pese a su escasa ambición transformadora, no llegó a ser aprobado (10). Otros autores, sin embargo, llegaron mucho más lejos en sus propuestas y no se conformaron con leyes o normativas más o menos paliativas y, desde luego, difíciles de cumplir sin una infraestructura sanitaria que intentara cubrir las necesidades sanitarias de la población. La creación de un Ministerio de Sanidad, como máximo órgano rector y coordinador de la Sanidad Pública española, fue reivindicada con cierta frecuencia, y de manera más o menos explícita, a lo largo del primer tercio del siglo XX. El objeto de las páginas que siguen es analizar los contenidos de dichas propuestas y valorar el papel jugado por médicos y políticos en el debate sobre la presencia o no de un Ministerio de Sanidad en el diseño de la estructura sanitaria española.

\section{Las primeras propuestas}

Casi con toda seguridad, la primera referencia que puede encontrarse en la literatura española sobre la necesidad de un Ministerio de Salud Publica es la aparecida en un difundido articulo de Philip Hauser titulado «EI siglo XIX bajo el punto de vista médico-social» y publicado en la Revista de España en 1884 (11). Se trata de un documentado texto en el que, tras exponer las novedades que en los modos de enfermar tuvieron lugar en Europa como consecuencia del proceso de industrialización y de los cambios sociológicos acaecidos en la segunda mitad del siglo XIX (12), concluye en que

«La sociedad, presentando cada día ejemplos nuevos que demuestran lo defectuoso de su organización y la insuficiencia de los medios de que 
dispone para mitigar los efectos del movimiento vertiginoso del progreso, e impulsada por otro lado, por el instinto de su propia conservacion, ha la imperiosa necesidad hombres de ciencia y a los más inteligentes de aquellos ramos que intervienen en los asuntos de la salubridad pública y privada, para que se reúnan y estudien la solución de este problema social tan complejos (13).

Resalta Hauser las iniciativas que, en este sentido, se estaban desarrollando, en el plano internacional, en torno a los Congresos de Higiene, en especial el celebrado en París en 1878, donde nada menos que E. Chadwick defendió por primera vez la necesidad de que todos los servicios referentes a la salubridad pública estuvieran centralizados y regidos por una institución gubernamental del más alto rango administrativo. Como es sabido, Edwin Chadwick, al frente de una "Comisión real» encargada de investigar las funciones y el grado de ejecución de la legislación sobre asistencia pública en la Inglaterra de 1832, fue el principal impulsor de la Rew Poor Law, aprobada por el Parlamento británico dos años más tarde. Desde el punto de vista de la organización administrativa, la principal novedad que introducía la Ley era, como ha señalado G. Rosen, «la tendencia a la centralización, la unificación y la eficacia» (14). En lo referente a la Salud Pública, su principal aportación fue el Report (...) on an inquiry into the Sanitary Condition of the Labouring Population of Great Britain, publicado en 1842, que facilitó un cambio de orientación de la Sanidad Públi$\mathrm{ca}$, otorgando un mayor protagonismo a los aspectos técnicos - de ingeniería e infraestructuras sanitarias-, aunque sin olvidar los estrictamente médicos. Ya entonces, y desde esta perspectiva, el autor inglés planteaba la necesidad de un órgano administrativo que llevase a la práctica un programa preventivo que garantizara de forma eficaz y consecuente la aplicación de los saberes técnicos (15).

Comparando las funciones de un posible Ministerio de Sanidad con el incuestionable Ministerio de la Guerra, el político británico argumentaba que «el combate para [el] que teńdría que prepararse el Ministerio de Salud Pública es de todos los momentos, pues el enemigo que tiene que combatir es un invasor perenne que siempre está dispuesto a dar y ganar batalas, que causa numerosas víctimas y muchas veces grandes desastres para la nación» (16)

El enorme auge de la bacteriología a finales del siglo XIX, y de lo que Pedro Laín ha denominado "mentalidad etiopatológica» (17), explica la utilización simbólica del discurso bélico en el enfoque sanitario general.
El descubrimiento de la acción patógena de numerosos agentes microbianos contribuyó a que las enfermedades infecciosas se consideraran simples «entidades morbosas» que podían evitarse con remedios médicos vacunas, antibióticos, etc.--, perdiendo así gran parte de su tradicional componente social (18). Todo un ejército microscópico, cuya amenaza era preciso combatir con barreras defensivas - la citada infraestructura de saneamiento (evacuación de excretas, recogida de basuras, control de al gunos productos, etc.) - y con todo un arsenal científico de terapias preventivas o curativas que precisaban, para su adecuada coordinación, un Estado Mayor Sanitario.

Defender a la nación, precisaba, en el sentir de Hauser, una medicina pública, entendida como "el apoyo y la ayuda material de los poderes públicos" a los esfuerzos de los científicos. Apoyo que habría que traducirse en «una legislación sabia y previsora trazada por personas experimentadas y con la colaboración de todos los hombres competentes del ramo, y confiar su ejecución a un Ministerio especial, llamado de Salud Pública» (19).

La vocación legislativa es, como se sabe, una de las características definitorias tanto de la vieja Policía Médica como de la Salud Pública. La necesidad de intervenir sobre lo colectivo a través de leyes y normas sanitarias está presente en la obra de prácticamente todos los salubristas modernos y contemporáneos, desde Seckendorff, para el que «la función que corresponde al Estado es la de dictar disposiciones que garanticen el bienestar del país y del pueblo» (20), hasta las propuestas políticas de Virchow o Neumann en el seno del movimiento de Reforma Médica surgido en plena revolución de 1848 (21). La tendencia de la Higiene Publica, desde su propia formulación como disciplina científica, es la de ir afianzándose, cada vez más, como parte integrante del aparato político del Estado. Por eso, en un primer momento, y durante mucho tiempo, la sanidad dependerá de secciones administrativas con mentalidad policial (Gobernación, Interior, etc.).

La propuesta de Hauser para España, como la de Chadvick en Inglaterra, no parecen responder, a mi modo de ver, a una novedad significativa de estos planteamientos; se insiste, en efecto, en la necesidad de que el Estado asuma la custodia de la salubridad pública pero la reivindicación de un Ministerio propio va más encaminada a centralizar las labores higiénicas y a conseguir una mayor eficacia de la acción sanitaria que a despojar a la misma del halo de paternalismo autoritario que siempre había tenido. De hecho, al final de la disertación, se suaviza mucho la defensa de una cartera específica si de otra manera - a través de una sec- 
ción especial con legislación propia- se puede obtener el poder y la autoridad necesarios para «imponer a los municipios todas las mejoras de saneamiento y de higiene urbana que estime conveniente en beneficio de los administrados» (22).

\section{Crisis sanitaria y poder médico}

Aunque la idea de crear un Ministerio de Sanidad volvió a plantearse, de manera aislada, en el Congreso Internacional español de la tuberculosis celebrado en Barcelona en 1910 (23), habrá que esperar a la segunda década de este siglo para encontrar nuevamente en la literatura médica elaboraciones al respecto $y$, en definitiva, la cristalización de todo un discurso éncaminado a desarrollar la administración sanitaria española. La epidemia de gripe de 1918-19 supuso un enorme agravamiento de la situación sanitaria del país (24), el aumento de la mortalidad general y de la infantil y el recrudecimiento de ciertas endemias como la temida tuberculosis, supusieron un importante revulsivo para la opinión pública (25) y sanitaria a la hora de reclamar soluciones. Los informes antes citados de Pulido, Martín Salazar o Murillo, advirtiendo y criticando el estado de la sanidad pública en España, quedaron cortos ante la magnitud de una enfermedad catastrófica cuya aparición coincidió con una crisis política y económica sin precedentes (26)

La creación de un Ministerio de Sanidad, como eje central de una necesaria reforma sanitaria, fue objeto del interés de una buena parte del colectivo profesional que no dudó en vertir sus opiniones en órganos de expresión especializados o a través de prestigiosas y combativas instituciones.

Las páginas de La Medicina Social Española (27) hicieron repetidaș alusiones a la urgente necesidad de una reforma administrativo-sanitaria profunda (28), pero fue La Medicina Ibera, la que en octubre de 1918, tras la constatación del «fracaso absoluto de nuestra organización sanitaria» (29), lanza una campaña de información y concienciación entre la profesión médica española de la necesidad de crear el Ministerio de Sanidad. Fernando Coca, director de la publicación, explicaba así el proyecto editorial:

«El divorcio que domina entre el cargo político y el cargo técnico da como fatal resultado la inutilidad absoluta de todos los esfuerzos encamina- dos a mantener el normal estado sanitario de la patria. Por eso La Medicina Ibera considera preciso, absolutamente preciso, emprender una enérgica campaña en pro de la creación de una entidad autónoma, de un Ministerio, que además de la iniciativa tenga la responsabilidad de cuanto con la sanidad esté relacionado, constituyendo un todo orgánico que comprenda desde la más prestigiosa personalidad técnica al último médico rural» (30).

Así, a lo largo del otoño de 1918, la mencionada revista publicó el resultado de una encuesta dirigida a distintas personalidades de la Medicina y de la Sanidad sobre la conveniencia o no de crear el consabido Ministerio. José Valenzuela y Esteban Rodríguez Ocaña, en un breve pero ajustado estudio de dicha encuesta, llegan a la conclusión de que «En 1918 parece existir una opinión mayoritariamente favorable a la instauración de un Ministerio de Sanidad, entre un destacado segmento de profesionales ilustres, políticos, catedráticos y directores de prensa médica». La creación del mismo se justificaba, en opinión de estos autores, «por la situación de desajuste administrativo, por la elevada mortalidad habitual y por las reivindicaciones de los médicos titulares» (31).

Ahora bien, esta "opinión mayoritariamente favorable» queda, a veces, un tanto desdibujada por la desconfianza de los profesionales hacia la enorme inestabilidad política del país. El propio F. Coca, resume así, en términos muy duros, el resultado de la encuesta:

«Todos consideran como vitalmente preciso la creación del Ministerio de Sanidad, y aquellos que exponen algunos reparos, hacen la objeción sólo a título de esa desconfianza que en todo español han logrado despertar las repetidas farsas de nuestros políticos, más atentos al lucro y al beneficio personal que al bien colectivo de la patria. Temen los que ponen en entredicho los beneficios del Ministerio de Sanidad, que esta nueva organización venga a constituir, dentro de nuestra política podrida, un nuevo cacicazgo, otro departamento en donde los que de la política hicieron profesión, puedan bucear con fines bastardos, dificultando todavía más la misión altamente humanitaria, que debe estar encomendada a quienes velen por la salud de sus compatriotas» (32).

No es de extrañar: el descrédito de los múltiples gobiernos que se van sucediendo al frente de la Nación, así como la compleja y agitada situa ción socio-económica, motivaron una crisis de hegemonía y de autoridad que explica la desconfianza de un amplio sector del colectivo médico hacia el poder político. El propio Ramón y Cajal, con cuyo indiscutido pres- 
tigio científico se abre la serie de encuestas realizadas por La Medicina Ibera "sobre la creación de un Ministerio de Sanidad», opina que, dicha empresa

«me parece de perlas y sumamente oportuno en las actuales circunsin paréceme que nuestras eminencias políticas ta no accederán a la creación de
siente poco la higiene...» (33).

Con mayor o menor grado de matización, la idea es repetida por muchos facultativos, bien de manera general: «En España estamos en un abandono sanitario; los políticos no se han ocupado con la debida atención de las cuestiones sanitarias" (34); bien, argumentando la necesaria independencia política de un Ministerio que, entienden, debe ser eminentemente técnico, ya que éstos - los técnicos- habitualmente fracasan en sus propuestas y «pierden un tiempo fabuloso para convencer a sus excelentísimos de la necesidad de tal o cual medida» (35). En esta misma línea de pensamiento cabe ubicar las opiniones de los directores de la revista España Oftalmológica, al condicionar la creación del Ministerio a que su titularidad «fuese ejercida por técnicos profesionales que hayan luchado contra las lacras y miserias que destrozan a los españoles, por médicos, en fin, u otras clases sanitarias...», mostrándose, sin embargo, contrarios al mismo si «hubiese de crearse para ser desempeñado por políticos puros y ayunos de todo conocimiento médico" (36).

Por eso se argumenta con insistencia que «El Ministerio de Sanidad habría de gozar de cierta autonomía e independencia, permaneciendo completamente ajeno a los cambios de la política; yendo a él no los que contasen con el apoyo de los jefes de partido, sino los técnicos capacitados que contaran con la confianza de la clase» (37). Otros llegan mucho más lejos: Ruiz Maya -director del Ideal Médico- no sólo se muestra de acuerdo con que «Este ministerio no estará sometido a los cambios políticos del gobierno», sino que, llevando su desconfianza política a un límite extremo, acaba proponiendo drásticamente que «no podrá ser titular de este Ministerio ninguna persona que haya actuado en la política de estos este Ministerio ninguna pers
últimos treinta años» (38).

Es ésta una idea, asumida de manera prácticamente unánime, que vie ne a explicitar, en mi opinión, no tanto un supuesto enfrentamiento entre "clase política» y "clase médica», sino el interés de los médicos en ser tenidos en cuenta por las instancias del poder, o, dicho de otro modo, en in- tervenir, como he indicado con anterioridad, en las decisiones políticas Tal aspiración, sin embargo, es formulada de maneras muy diversas: desde la cauta reflexión de que "no sólo debemos pedir ministerio sino ministros» (39), hasta su utilización como argumento para negarse, al menos por el momento, a la creación del Ministerio, porque "un Ministerio de Sanidad sería eso, un Ministro, ante todo un hombre político afiliado a ésta o a la otra mesnada» (40).

Desconfianza hacia los políticos y búsqueda de un papel de mayor protagonismo social y político que, en el fondo, no abriga sino el deseo de que la medicina sea finalmente aceptada como "el gobierno de los pueblos en nombre de la salud» (41). La ambigua elocuencia del catedrático de Higiene de la Universidad Central, Rafael Forns, es significativa en este sentido; tras manifestarse abiertamente contrario a un Ministerio de Sanidad, por entender que «vendría al mundo con vicio hereditario de padre y madre, porque no gozan de lozana salud física ni moral, tanto la política como el protomedicato", aventura su propia definición de "medicina política» como «el arte de gobernar a los pueblos según conviene a la naturaleza humana, con objeto de hacer larga, próspera y feliz la vida individual y colectiva. $O$, en otros términos, es la aplicación de la Medicina a la política, a la gobernación de los pueblos y al perfeccionamiento de las razas» (42).

Se trata, en efecto, de un discurso equívoco y, desde luego, poco realista. La defensa a ultranza de la total autonomía médica frente a cualquier otra instancia administrativa está, por definición, condenada al fracaso. La medicina, y más si era entendida como la gran ciencia regeneradora de hombres y naciones, debía basarse obligatoriamente en «la transformación completa de nuestra política sanitaria, una remoción de los actuales organismos administrativos, la creación de órganos adecuados para la suprema función de garantizar la salud pública, primer deber de los estados modernos y el más sagrado deber individual que ha de consagrarse en las futuras constituciones políticas». A ello aspira el Instituto de Medicina Social, fundado en Madrid en 1918 (43), con el objetivo expreso de contribuir a la regeneración sanitaria, la educación de la población y la motivación de las autoridades políticas hacia los asuntos relacionados con la sanidad, asî́ como el estudio y la investigación de aquellos problemas sociales que la Medicina Social podría contribuir a solucionar (44)

Ahora bien, tras el análisis de la cuestión social en relación con la medicina, el pragmatismo del Instituto le lleva a propugnar la acción po- 
lítica y la propaganda para que «con el tiempo, tomen estado parlamentario estas cuestiones y sean parte esencial del programa de los gobiernos» (45).

La vocación política del Instituto de Medicina Social queda patente. La constitución de un "poder médico" suficientemente reconocido en las esferas de la alta política resulta imprescindible, en opinión de los dirigentes del Instituto, para conseguir llevar adelante su proyecto regenerador. La independencia de ese poder sanitario es apuntada como elemento necesario para la continuidad de sus propuestas, pero de ninguna manera es utilizada como bandera reivindicativa que dificulte el entendimiento con los poderes legislativo y ejecutivo. Así, los Estatutos del Instituto especifican que uno de los fines del mismo es «ejercer la necesaria acción política hasta conseguir del Estado el reconocimiento y la independencia del poder sanitario y la creación de órganos oficiales encargados de sostenerle» (46).

En este sentido, resulta explicable la presencia como socio fundado del Instituto, y junto a médicos e higienistas de gran prestigio (47), de Manuel Burgos Mazo, ministro de Gobernación durante el efímero gobierno de Sánchez Toca - de junio a diciembre de 1919-. Tampoco parece una casualidad que, precisamente durante su gestión, las actividades del Instituto obtuvieran un cierto eco y apoyo oficial (48). Apoyo que hubiera sido imprescindible para conseguir la creación de un Ministerio de Sanidad, considerado, como fácilimente puede deducirse de los textos citados, uno de los objetivos concretos más claros del Instituto.

En un pedagógico folleto, editado por el propio Instituto, se explicaba así la importancia de la Medicina Social y la necesidad de «la transformación completa de nuestra política sanitaria» (49):

«Un sujeto, obligado a residir en una población de aguas sospechosas las filtra cuidadosamente antes de beberlas. Esto es Higiene individual.

Otro sujeto, más ignorante o más desaprensivo, olvida estas precauciones y enferma. El médico le asiste. Esto es Medicina individual.

El Municipio, en vista de la repetición de casos, dispone la esterilización de las aguas para destruir los gérmenes patógenos. Esto es Higiene Pública.

Pero un Ministerio de Sanidad impone a todos los Ayuntamientos de un país la obligación de abastecer de aguas potables a las poblaciones en un plazo determinado, facilitándole la ayuda económica y técnica necesaria. Esto es Medicina Social» (50)
Es este poder ejecutivo, esta autoridad para imponer normativas y actuaciones sanitarias, incluso a los poderes locales, uno de los aspectos que vinculan más claramente el siempre abstracto "poder médico» con la reivindicación concreta de un órgano sanitario máximo perteneciente a la Administración central del Estado.

Se trata de una línea de pensamiento enormemente extendida entre los profesionales con vocación política. Francisco Rico Belestá, en sus columnas sobre "Política e higiene» publicadas en El Siglo Médico como sección fija, denuncia, una vez más, el descuido de los gobiernos, aboga por una política higiénica «de la que nacerán diputados higienistas que serán los verdaderos defensores de la Patria y guardadores celosos de la Higiene Pública» (51) y termina ubicando el eje central de las reformas y de las nuevas leyes y reglamentos sanitarios en un Ministerio de Sanidad. "El día que llegue a triunfar -escribe- la nueva política higiénica el elector o pueblo quedará convencido, y entonces vendrá la verdadera depuración de responsabilidades de los que han creado una España degenerada y una excesiva mortalidad por nadie superada, hecatómbica y horrorosa» (52).

Soberanía absoluta, derecho de ejecución, jurisdicción sin apelación. Todo eso se pide para un Ministerio convertido en brazo armado de un poder médico llamado a convertirse en salvador de la Patria. No es una casualidad, a mi entender, que mientras se gestaba el fin de la Restauración, y su sustitución por el Directorio militar de Primo de Rivera, en las páginas de las publicaciones sanitarias encontraran espacio opiniones que, retomando el viejo símil castrense, demandaban la creación de un «ejército sanitario para defender la vida nacional» o, simple y llanamente, «una dictadura sanitaria», llegándose, incluso, a insistir en que "no podría realizarse con garantía de éxito esa revolución sanitaria sin antes llevar a cabo la del sistema de gobernarse» (53). Los prolegómenos de la dictadura de Primo llegaron a establecer un entramado ideológico del que, sin duda, era muy difícil prescindir.

3. Una propuesta parlamentaria: la Ley de Bases para la creación del Ministerio de Sanidad Social

Con el telón de fondo de la dramática situación sanitaria del país y, en parte, como respuesta a la insistencia del colectivo médico, constituido 
como grupo de presión más o menos organizado, no podemos dejar de considerar algunas iniciativas políticas presentadas en las Cortes Generales antes de su disolución en 1923. El hecho de que no fueran aprobadas, y apenas discutidas, por el poder legislativo no invalidan su interés sino que, al contrario, nos ofrecen, a mi juicio, una valiosa información sobre la existencia de propuestas y elaboraciones políticas en materia sanitaria que, al margen de sus contenidos y/o de su rigor metodológico desde el punto de vista de la ciencia sanitaria, fueron ignoradas sistemáticamente por diputados y senadores (54). Me refiero a la ya mencionada «Proposición de Ley de Profilaxis de enfermedades evitables» y a la "Proposición de Ley de Bases para la creación del Ministerio de Sanidad Social», presentada por el diputado por Las Palmas de Gran Canaria, Van-Baumberghen (55).

Esta última Proposición aparece por dos veces en el Diario de las Sesiones de las Cortes. Congreso de los Diputados, el 20 de enero de 1920 (apéndice 4 al número 54) y el 13 de abril de 1921 (apéndice 14 al número 37). En ambas ocasiones el texto se repite íntegramente, cambiando tan sólo el encabezamiento ya que el hipotético Ministerio de «Sanidad Social» pasa a denominarse de «Sanidad Civil». Es lógico suponer que las continuas crisis ministeriales obligaran a presentar la misma proposición más de una vez y que, en muchas ocasiones, ni siquiera llegara a discutirse (56).

Con todo, en mi opinión, el interés de dicha Proposición de Ley es doble; por un lado, es la primera iniciativa política - parlamentaria-que plantea la creación de un Ministerio de Sanidad en nuestro país, lo cual ya de por si tiene un valor histórico intrínseco. Pero, por otro lado, el acercamiento metodológico del análisis y de la propuesta no parte de los presupuestos médicos y sanitarios ya comentados, sino que se basa en el intento de adecuar la salud pública y los servicios asistenciales a objetivos tendentes a garantizar la fuerza de trabajo, más que a «sanear» el país.

Aunque, como no podía ser de otro modo, Van-Baumberghen hace alusión a la penosa situación sanitaria del país, los datos demográficos que aporta — natalidad, mortalidad general, mortalidad infantil, mortalidad por enfermedades infecciosas- tienen como finalidad demostrar no tanto el estado de salud de la población española y su evolución a través de las dos primeras décadas del siglo, sino a argumentar la necesidad de medidas que, disminuyendo la mortalidad y aumentando la natalidad, garanticen el crecimiento de la población, al considerar éste como elemento clave en la "producción y conservación de los organismos generadores del esfuerzo».
El trabajo, entendido como la base de la estructura social, constituye, en efecto, el punto de partida del diputado canario, para el que el cumplimiento de este deber/derecho de todo ciudadano está sujeto a una serie compleja de factores, circunstancias y necesidades que se especifican en la exposición de motivos de la Proposición; detallado texto en el que se relaciona cada problema laboral con su correspondiente en el orden sanitario, siempre desde el convencimiento de que "cuantas cuestiones puedan plantearse en relación con el trabajo sólo pueden ser resueltas moviéndose dentro de los lindes de los conocimientos sanitarios» (57).

Como puede verse en la tabla I, donde se recogen las mencionadas correspondencias, la preocupación por la reproducción de la fuerza de trabajo es la que acaba modulando la identificación de problemas y de prioridades sanitarias. Temas frecuentes en la literatura medico-social vuelven a aparecer aquí perfectamente ubicados en relación con las necesidades planteadas en el orden laboral y económico de conseguir una mano de obra sana y abundante.

Desde una concepción muy mecanicista que reduce al hombre -al trabajador - a una simple máquina productiva, se asumen los principios fundamentales del Estado interventor encaminados a dirigir desde los poderes públicos la política económica y social, para lo cual era preciso garantizar, entre otras cosas, la protección de los trabajadores tanto desde el punto de vista biológico como social. Se contemplan así distintas intervenciones, que pueden resumirse en tres tipos de medidas fundamentales:

1. Medidas encaminadas a garantizar la renovación generacional de la clase obrera: aspectos eugénicos -como el control de los matrimonios- (58), de protección a la mujer embarazada y/o lactante (59), de paidocultura, etc.

2. Medidas higiénicas tendentes a procurar al trabajador un ambiente suficientemente «saneado» tanto en su puesto de trabajo (60), como en sus hábitos y modo de vida (61).

3. Medidas reparadoras para los trabajadores que, por distintos motivos (enfermedad común, accidente laboral, paro o vejez), dejan de ser aptos -temporal o definitivamente - para trabajar (62).

Se trata, sin duda, de un ambicioso plan de regeneración de las clases trabajadoras, siempre sospechosas de peligrosidad social (63), a la vez que se incorporan algunos de los postulados que los teóricos de la Higiene in- 
dustrial venían planteando desde hacía tiempo. El proyecto reformista y "regenerador» presente en la Proposición de Ley que nos ocupa toma de la Medicina -entendida como "gran ciencia social»-- argumentos en los que fundamentar la iniciativa política. No en vano, como ha indicado recientemente Esteban Rodríguez Ocaña, «Desde la Medicina (...) se ofrecían soluciones a las lacras de la sociedad industrial que, si bien no cuestionaban los marcos económicos ni políticos del problema, por lo que convenían a su legitimación, al mismo tiempo coincidían en la denuncia de unas condiciones de vida y trabajo mejorables en gran medida mediante la asunción de sus propuestas» (64).

De esta manera, la medicina social comienza a jugar un papel tendente a la conciliación entre las clases sociales y, en definitiva, al intento de intervenir sobre la llamada "cuestión social». Así lo expresa el diputado canario cuando indica que «a la lucha de clases sucede el odio de clases, y como chispazos de un porvenir cercano y sin sanción posible, sobreviene la violencia personal, preludio de mayores violencias, y con claudicaciones unas veces ante el fuerte, por imposiciones otras al que se estima débil, el poder público no ve otra salida que el legislar y legislar constante (...) legislación en suma que nada remedia, que hace más patente la injusticia» (65).

Preocupación por el orden público, desconfianza hacia los «gobiernos partidistas» ante la que el Parlamento se muestra impotente, ...pero sobre todo intento de superar el conflicto social mediante políticas sociales que suavicen la agresividad del viejo liberalismo económico. Recuérdese cómo el propio Lord Beveridge, en esta misma línea aunque algunos años más tarde, inicia su informe sobre el Pleno Empleo en una Sociedad Libre con la afirmación: «El sufrimiento engendra odio» (66).

Tampoco es de extrañar, en este sentido, que desde el reformismo y desde la medicina social se acuse al capitalismo de su afán de explotación y de sus consecuencias sobre el proceso de trabajo:

«A que el estado social presente se modifique, se opone el régimen capitalista actual, y dentro de él, no la capitalización justa del trabajo, sino la supercapitalización del mismo, o sea el incremento del capital no ganado por el trabajo propio, que, por una parte origina la transacción obligada del esfuerzo, legitimando la compraventa del mismo, produciendo y fomentando con ello la actual lucha de clases, y por otra da lugar al parasitismo social, fórmula odiosa de injusticia por la que se soslaya el cumplimiento del trabajo obligatorio» (67).
No conviene engañarse, sin embargo, sobre el alcance real de tales argumentos. El llamado Estado interventor no hizo sino modificar su propio aparato propiciando un aumento de las funciones tutelares en relación con la clase trabajadora. La intervención estatal en materia de salud -como en materia de trabajo- no cuestiona para nada la axiomática capitalista, sino que la refuerza en la medida en que supone una estrategia, como ya he indicado, para garantizar la paz social y frenar el avance del movimiento obrero; pero también, y sobre todo, para garantizar la reproducción de la fuerza de trabajo y hacer así frente a las crisis económicas (68).

Así, ante la imposibilidad de que se obligue «al Estado, anémico, empobrecido, exhausto de recursos económicos, a proveer y asistir a todas las necesidades sociales, mientras que los capitalistas aumentan sus enormes beneficios a costa del trabajo ajeno y de la misma debilidad del poder público" (69), no se duda en promover medidas extraordinarias para la financiación de un cierto Estado Social, como las nacionalizaciones (70) o la creación de nuevos impuestos (71). Sin embargo, a pesar de las desconfianzas hacia los políticos y las críticas hacia los dueños de los medios de producción; y a pesar de la propuesta de medidas sociales encaminadas a la redistribución de la riqueza, no se llega a cuestionar nunca el modelo de estructura socioeconómica imperante. Las palabras de nuestro bienintencionado diputado no dejan lugar a dudas: "en último extremo y en suma el ideal de la defensa de nuestra civilización, de su progreso y del bienestar, que es su consecuencia, no consiste, ni en el empleo de la fuerza, sostenida por los que poseen para contener los legítimos anhelos de los necesitados (teoría liberal de los individualistas), ni en no tener nada nadie, para que nadie nada tampoco apetezca (socialización total de la riqueza), está en que todos tengan algo que perder, en la seguridad de que nadie querrá perderlo (difusión de la riqueza por cese de la supercapitalización)» (72).

En definitiva, tras una larga y prolija exposición de motivos, se acaba proponiendo al Congreso de los Diputados un conjunto de diez Bases para la creación del Ministerio de Sanidad Social. La novedad organizativa más notable es, sin duda, la pretensión de englobar las competencias de sanidad, trabajo y previsión social en una misma cartera, contemplando la creación de tres Consejos Superiores: El Consejo Superior de Trabajo, donde quedaría acoplado el Instituto de Reformas Sociales, el Consejo Superior de Sanidad y el Consejo Superior de Previsión y Asistencia, donde quedarían encuadrados tanto la Beneficencia como el Instituto Nacional de Previsión. 
Se comienza así a apuntar la necesidad de una íntima colaboración entre la Sanidad Nacional y los Seguros Sociales. En lo concerniente a la Salud Pública propiamente dicha, la Proposición de Ley contempla, en su Base séptima, la profilaxis de las enfermedades infecciosas, haciendo especial hincapié en la declaración obligatoria, en la obligatoriedad de la vacunación antivariólica antes de los seis meses de edad y en la lucha antileprosa y antivenérea. Tales tareas, a las que hay que añadir el cuidado y vigilancia de los alienados - tradicionalmente a cargo de la Beneficencia del Estado-, se complementaría con la creación de seguros como el de accidentes, enfermedades en general, tuberculosis, invalidez, maternidad, etc. (73)

Asimismo. al establecerse la relación de los organismos sanitarios con los de trabajo, se prevé la creación de Jefaturas de Sanidad y de Trabajo regionales, provinciales y de distrito, que funcionarán con «entera independencia de toda otra autoridad gubernamental, en locales y con perso nảl y material propio" (74). Con ello, y con la mención expresa de que "Todos los inspectores de Sanidad y del Trabajo serán remunerados directamente por el Estado» (75), se responde a una de las más viejas aspiraciones de los médicos titulares, su conversión en un Cuerpo de funcionarios del Estado (con sueldo fijo y asegurado, montepíos de jubilación e invalidez, etc.) independientes del poder local de los alcaldes y los caciques de la España rural (76).

A modo de reflexión final, no creo que sea demasiado arriesgado encuadrar esta propuesta de creación de un Ministerio de Sanidad, a pesar de la época en que es formulada, en una línea de pensamiento próxima al Estado Social de Derecho. Un modelo de Estado cuya formulación teórica se va fraguando desde los años de transición del siglo XIX al XX y que culminará, ya en la segunda post-guerra mundial, en el Estado del Bienestar propio de los países europeos capitalistas industrializados (77). Elementos como la participación directa del Estado en la financiación, administración y gestión de los servicios públicos, así como la regulación de las actividades empresariales privadas o la política de nacionalizaciones son aspectos que aparecen en la Propuesta de creación del Ministerio de Sanidad en nuestro país y que recuerdan, en parte al menos, al ideal fabiano de una sociedad en la que desaparezca el totalitarismo, el sufrimiento y la miseria (78). Junto a ello, resulta imprescindible, en el sentir de los teóricos del «bienestar», garantizar la producción, así como una cierta redistribución de la riqueza, que permita, poco a poco, la superación de las diferencias adquisitivas y, en definitiva, la conciliación entre las clases en lucha (79).

No deja de resultar llamativo que en la España subdesarrollada, desindustrializada y en permanente crisis política pudieran llegar a plantearse propuestas tan audaces como inviables, aunque fuesen aisladas, de tal envergadura.

\section{Sanidad y trabajo}

Salvo el Reglamento de Sanidad Municipal, promulgado en febrero de 925, la dictadura de Primo de Rivera no introdujo cambios significativos en la administración sanitaria civil (80), siendo ya durante la República cuando parece retomarse de nuevo la preocupación por el Ministerio de Sanidad. El debate se va a desarrollar, a partir de entonces, en dos niveles de discusión diferentes: uno más político, la oportunidad o no de crear el nuevo Ministerio, y otro más técnico sobre la manera de encajar administrativa y organizativamente las competencias de Sanidad. Analicemos a continuación las dos cuestiones, aunque no por separado puesto que, como no podía ser de otro modo, aspectos políticos - de modelo-y organizativos se entremezclan con frecuencia en las distintas propuestas o posturas sobre el tema.

El debate en torno a la unificación de los servicios de sanidad y asistencia en un solo organismo gubernamental y, en definitiva, la propuesta de creación de un Ministerio de Sanidad es uno de los elementos organizativos básicos propugnados por la Unión General de Trabajadores al comienzo de la II República. La Ponencia oficial que sobre «Política Sanitaria» presentó Sadi de Buen al XVII Congreso de dicho sindicato celebrado en 1932, comenzaba diciendo:

"Todos los servicios de sanidad y asistencia deben quedar vinculados en una única organización de categoría administrativa suficientemente elevada (ministerio) para permitir la mayor autonomía posible» (81).

Durante el primer bienio republicano, sin embargo, con ministros socialistas en el gobierno, no se llegaron a introducir cambios en este sentido, permaneciendo la sanidad dentro de las competencias de Gobernación. Antonio Mazuecos ha achacado esta actitud remisa, por un lado, a un propósito de simplificación burocrática y, por otro, a una fundada desconfianza hacia los médicos españoles y hacia la «proyección político-social de la labor médica», creyéndose necesaria, desde las filas socialistas, una «intensa la- 
bor de concienciación para dar a la clase sanitaria española una dimensión política, que por si misma exigiera la creación del Ministerio» (82).

No deja de resultar interesante la diferencia de criterios entre el PSOE y la UGT, pero lo es más la constatación de que esta vez son los políticos los que muestran su desconfianza hacia los médicos y hacia sus posibilidades de colaboración en el plano político-sanitario. Hemos visto con anterioridad la postura de determinados médicos sobre las relaciones entre medicina y política y su vocación legislativa, normativizadora y "regeneradora»; no podemos olvidar, sin embargo, que salvo los higienistas -encargados de dirigir y coordinar la Sanidad Nacional y acostumbrados por tanto a pensar en términos de Salud Pública-y los médicos titulares —obligados a compaginar tareas de inspección sanitaria y de asistencia benéfica sin demasiados alicientes económicos ni profesionales-, la gran mayoría del colectivo médico, agrupado en torno a Colegios profesionales y asociaciones corporativas, defendió a ultranza el ejercicio liberal de la profesión, contrario siempre a instituciones como el Seguro de Enfermedad o a organismos estatales centralizadores o controladores de su actividad (83).

No será hasta 1933, con Alejandro Lerroux como presidente del Consejo de Ministros, cuando se produzca un intento de "racionalización" de la organización sanitaria haciendo depender las competencias de Sanidad y Beneficencia del Ministerio de Trabajo. Se retomaba, así, una vieja polémica sobre la ubicación administrativa de la Sanidad Nacional, lo cual implicaba, en si misma, la discusión sobre el modelo de sistema de salud adoptado por el Estado. La adscripción de la Dirección General de Sanidad a Gobernación contenía innegables reminiscencias del papel policial y represivo achacado a veces a la Salud Pública. Pero, aunque la propuesta de un Ministerio de Sanidad autónomo era defendida por muchos, no faltaron quienes consideraron más pertinente agrupar competencias y abordar de manera conjunta problemas relacionados entre sí. El prestigioso e influyente J.M. Cortezo había defendido en 1918 la inclusión de Sanidad en Fomento por entender que «los problemas de este ministerio son problemas relacionados con el Comércio, la Navegación, la Industria, la Arquitectura y la Agricultura, problemas que se hallan todos ellos en íntima relación con las cuestiones sanitarias» (84).

Con todo, es la adscripción al Ministerio de Trabajo la que, como hemos visto, se plantea con mayor insistencia. Como ha indicado Mercedes Samaniego, las imposiciones presupuestarias de índole global obligaron al gobierno de la República a disminuir el número de Departamentos ministeriales, unificando gestiones en torno a una sola cartera (85); sin em- bargo, no parece que los motivos íntimos de este trasvase de competencias desde Gobernación a Trabajo se debieran exclusivamente a razones de ajuste presupuestario, toda vez que más que supresión de unidades administrativas, lo que se produjo fue una transformación de la Subsecretaria de Sanidad y Beneficencia - perteneciente al Ministerio de Gobernación- en otra que, con el mismo rango de subsecretaría, se denominó de Sanidad y Previsión y pasó a depender, como ya he indicado, de un renovado Ministerio de Trabajo, Sanidad y Previsión (86)

El trasfondo ideológico del nuevo planteamiento parece claro: por un lado, ante la inminente implantación del Seguro Obligatorio de Enfermedad, asimilar el concepto de Salud al de Previsión; por otro, hacer depender del Ministerio de Trabajo unas competencias y unas reformas cuyo principal beneficiario habría de ser la clase trabajadora. Se mantiene así, con más o menos matizaciones, la filosofía de Van-Baumberghen de la intima relación entre problemas laborales y sanitarios, así como la supeditación de estos últimos a la reproducción de la fuerza de trabajo.

Un decreto del 25 de diciembre de 1933, siendo ministro de Trabajo José Estadella, establece definitivamente la adscripción de Sanidad a la cartera de Trabajo (87). Dicho decreto fue convalidado por Ley del 16 de marzo de 1934 tras una larga y acalorada discusión en las Cortes cuyo seguimiento puede ofrecernos claves interesantes para valorar el modelo de política sanitaria defendida por las distintas fuerzas con representación parlamentaria (88).

La encendida defensa que el propio Estadella realizó ante el Pleno del Congreso de los Diputados nos ilustra suficientemente sobre el talante de las propuestas de los radicales. Se lamenta el Ministro de la situación sanitaria del país, cuyos pueblos "sólo recibieron de la ciudad el alcoholismo, la lúes, la tuberculosis, etc., por conducto de los mozos que volvían del cuartel o de las muchachas que retornaban del servicio doméstico; enfermedades que han llegado allí, y que por no haber encontrado un solo muro de contención se han extendido a voluntad. $\mathrm{Y}$ bien, yo digo a la Cámara que en esos pueblos se fragua el desgaste, la ruina física y moral de la raza nuestra, y que es necesario, absolutamente necesario, correr a ellos en auxilio de tantos males» (89).

Resulta interesante constatar la referencia concreta a las tres plagas blancas - la tuberculosis, la sífilis y el alcoholismo-, las tres enfermedades sociales por excelencia, asociadas tradicionalmente a la pobreza y utilizadas frecuentemente como símbolos de decadencia orgánica y social. La preocupación por la degeneración de la raza es habitual en el reformis- 
mo burgués del finales del XIX y primeras décadas del XX, que aspirará, mediante programas de reformas sociales, a «regenerar» al país y paliar los problemas derivados de la llamada "cuestión social» (90).

En este afán de reforma, y como parte de sus argumentos para acometerla, Estadella critica duramente la Beneficencia como un sistema asistencial obsoleto y totalmente ineficaz.

4hí están -manifiesta - esas colas infinitas, dolorosas, de enfermos que esperan a la puerta de hospitales y sanatorios turno para ingresar en ellos, y mueren antes de que el turno les haya llegado; ahí están esas falanges de mujeres semihambrientas, enfermas, desconociéndolo ellas mismas, con las entrañas fecundas (...) donde florece una ciudadanía que forzosamente ha de ser morbosa; ahí están esos manicomios pestilentes, hacinados, vela donde la inteligencia desviada no recibe el apoyo respetuoso y caritativo que el Estado le debe» (91).

Se hace, pues, necesaria una remodelación tanto de la Sanidad Nacioal como de la asistencia pública. Las razones fundamentales por las que, según el gobierno, debe ser el Ministerio de Trabajo el encargado de llevarla a cabo quedan resumidas en las palabras de su responsable, cuando indica que en su Departamento «la preocupación ha consistido, en cosas de salarios, y en general, de bases de trabajo; pero el Ministerio de Trabajo, hasta aquí, se ha preocupado muy poco de las cuestiones que hacen referencia al ambiente de trabajo mismo, al ambiente donde el trabajo s desarrolla y tiene lugar. No se ha estudiado al obrero como un ente biológico de la producción; apenas si se ha tocado lo referente a enfermedades profesionales; no se ha estudiado nada sobre la potencialidad, sobre la capacidad de trabajo de la mujer y del niño; no se ha estudiado nada en orden a la alimentación del obrero ni en orden a la vivienda del obrero. $Y$ todo esto entra de lleno en el área de las cosas sanitarias y de la asistencia pública, y le parece al gobierno, y me parece a mí, que no es ningún dislate situar las cosas de la sanidad y de la asistencia pública (...) en el Ministerio de Trabajo» (92)

Un proceso político se había puesto en marcha; no se puede olvidar que el INP fue el organismo encargado de elaborar y poner en funcionamiento todos los seguros sociales en España; el de paro, el de vejez, el de invalidez, etc., pero también el de enfermedad, y es lógico suponer que los técnicos del Instituto no se resignaran a perder el control de uno de los seguros más esperados sobre el que forzosamente habrían de recaer cargos, partidas presupuestarias, etc., existiendo el riesgo, más que en ningún otro seguro, de una derivación hacia instancias ajenas a Trabajo. «La unidad teórica del servicio sanitario - se argumentará - no debe destruir la unidad de la institución del seguro de enfermedad ni la unidad del conjunto de los seguros sociales» (93). Razón de peso para que sus responsables pretendan hacerse cargo de Sanidad y para que se asimile tan insistentemente Sanidad con Previsión.

El resto de las minorías parlamentarias mostraron su desacuerdo con la iniciativa gubernamental. Dichas minorías, desde la republicana-conservadora, representada por Martínez Arenas, hasta la socialista, cuya portavoz en el debate fue Margarita Nelken, se manifestaron partidarios de la creación de un Ministerio de Sanidad, pronunciándose, prácticamente, en el mismo sentido, con intervenciones del siguiente tenor: "no parece lógico que ante una posibilidad de creación del Ministerio de Sanidad, sea hoy tan preciso y tan necesario el traspaso de los servicios de $\mathrm{Be}-$ neficencia y Sanidad, de Gobernación a Trabajo" (94).

El ejecutivo, en un intento conciliador, asumió la necesidad de crear "cuan to antes un Ministerio de Sanidad y Asistencia Pública», si bien justificó su postura insistiendo en que «el gobierno ha querido que antes de esta empresa magna le precediera un período de preparación para recoger todas las disciplinas sanitarias que andan dispersas en los otros Departamentos ministeriales y conectarlas, ordenarlas, verlas de cerca, conduciéndolas de tal suerte que rindan una mayor eficacia dentro de la mejor compañía posible» (95). Justificación que no solo resultaba difícil aceptar sino que motivó la contundente contestación de la oposición:

«...vayamos ahora a la creación de ese ministerio (el de Sanidad); más lo que no debemos hacer es traspasar en este momento esos servicios de Gobernación a Trabajo, para después sacarlos de ese ministerio y llevarlos al que se cree de Sanidad. Esto nos parece inconveniente, caro y entorpecedor» (96).

Intento de control, desde el INP, de las necesidades sanitarias del país frente a la pretensión de crear un ministerio nuevo con autonomía propia Este es, sin duda, el elemento central del debate, aun cuando Margarita Nelken se perdiera en tecnicismos sobre los defectos de forma a la hora de gestionar en la Comisión parlamentaria correspondiente el proyecto de gobierno, o llegara a manifestar que "si con algún organismo tenían nexo indisoluble los servicios de Sanidad es con Gobernación, porque si se trat de algo tan sencillo como obligar a vacunarse a una población refractaria 
como de medidas que hay que tomar en caso de epidemia, no será Trabajo, sino el Ministerio de Gobernación con sus autoridades subalternas, el que podrá adoptar esas determinaciones» (97).

De esta manera, la portavoz socialista introduce en el debate uno de los aspectos más complejos en la discusión sobre las funciones de la Salud Pública: el papel de control social que, a través de medidas coercitivas llevadas a cabo por los aparatos del Estado, puede desempeñar no ya sobre determinados grupos de riesgo sino sobre la población en general (98). No deja de resultar esclarecedor que las palabras de la diputada estuvieran inspiradas, como ella misma reconoce, en los argumentos expresados ante la Comisión "por un miembro de la minoría conservadora». No es de extrañar tampoco que el gobierno se limitara a replicar que «el Ministerio de Gobernación ofrecía a la Sanidad y a la Asistencia Pública un ambiente saturado de preocupación por el orden público, con muchos fusiles, tricornios y ametralladoras y con una complicada pirámide de expedientes de administración local» (99).

Se trata, no cabe duda, de una cuestión polémica sobre la que aún hoy día se sigue discutiendo. No puedo dejar de constatar, sin embargo, la a mi juicio dudosa oportunidad de su planteamiento por parte de una diputada socialista, no solo por motivos ideológicos - ya que las razones de orden público han sido tradicionalmente esgrimidas por la derecha-, sino porque tales argumentos se contradicen directamente con las ideas básicas de la Ponencia de "Política Sanitaria» aprobada en el Congreso de la UGT del año 32. En dicho texto, aunque se reconoce que ante "grandes epidemias y enfermedades pestilenciales las autoridades sanitarias deben contar con una legislación de excepción», se pone especial énfasis en la necesidad de «evitar los métodos coercitivos, sentando la actuación sanitaria sobre la educación, la propaganda, las visitas domiciliarias y por cuantos métodos sean útiles para acostumbrar a los ciudadanos a la tutela sanitaria y a seguir los consejos de ella derivados» (100). Si a esto añadimos, según hemos visto anteriormente, la apuesta decidida del sindicato socialista por la creación de un Ministerio de Sanidad, parece evidente que la postura defendida por la Sra. Nelken puede calificarse, cuando menos, de arriesgada si tenemos en cuenta los objetivos concretos del debate parlamentario y el discurso sanitario que la izquierda estaba empezando a mantener (101).

En cualquier caso, a través de mecanismos más o menos adecuados, se prepara en España una sanidad para la clase trabajadora. Con evidente retraso, se comenzaban a dar las condiciones - sociales y políticas- pa- ra la implantación no solo de los seguros sociales sino para la superación del viejo modelo liberal de asistencia médica -medicina privada y asistencia a los pobres a cargo de la Beneficiencia del Estado, sin olvidar los primeros esbozos de atención médica "colectivizada» a cargo de Sociedades de Socorros Mutuos (102) - y su sustitución por lo que podríamos denominar modelo de Seguridad Social (103), inspirado en la fórmula bismarckiana de las Cajas de Seguro y, consecuentemente, en una concepción eminentemente curativa de la asistencia, destinada a la reproducción de la fuerza de trabajo y, por tanto, a la población cotizante y a sus familias.

Como se sabe, otra característica del mencionado modelo es la ausencia de coordinación entre los diferentes niveles de atención. De hecho, tras la implantación definitiva del Seguro Obligatorio de Enfermedad en el año 44, y durante muchos años, pervivió una clara separación entre las tareas preventivas, a cargo de la Dirección General de Sanidad, concebidas desde Gobernación como una responsabilidad de la «seguridad del Estado", y las prestaciones asistenciales a los trabajadores dirigidas y organizadas por el INP.

Aunque la situación socio-política del país era muy diferente, los intentos o, al menos, las teorizaciones sobre la necesaria coordinación entre Sanidad Nacional y el Seguro de Enfermedad que se producen en la II República no responden, en mi opinión, a la voluntad política de establecer un nuevo modelo en el que la atención curativa y las medidas profilácticas -individuales y colectivas- estuvieran integradas, una unificación de servicios sanitarios y de asistencia que muy bien pudiera haber encontrado en un Ministerio de Sanidad el adecuado soporte administrativo-burocrático (104). Por el contrario, ante la inminente creación del Seguro de Enfermedad, éste se encontraba con una ausencia casi absoluta de infraestructura en la que apoyarse, dada la precariedad de los obsoletos hospitales de la Beneficencia y la ausencia de redes asistenciales privadas que poder contratar - sistema seguido por el Seguro en otros países-. Sanidad Nacional era el único organismo que contaba con una cierta infraestructura, desde dispensarios antituberculosos hasta Centros de Higiene Rural, que sí hubieran podido ser utilizados por el Seguro; otra importante razón para que la Salud Pública fuera asumida por el Ministerio de Trabajo: los servicios quedaban teóricamente coordinados, sin modificar el modelo de sistema sanitario imperante en el grupo de los paises capitalistas desarrollados en el que la España republicana aspiraba a pertenecer.

Asclepio-Vol. XLV-1-1993 
Orden laboral

Orden sanitario

Creación del mayor número posible de los organismos necesarios.

Cultivo y desarrollo de los mismos.

Vigilancia para obligar a que la ejecución del esfuerzo se realice en las condiciones debidas.

Ganar intensidad productiva

beneficiando los años de duración del organismo productor.

Reparación de los principios activos consumidos por el esfuerzo.

Dar tiempo a la reparación del desgaste celular por el descanso.

Alejamiento o supresión de causas posibles o ciertas de innecesario desgaste.

Complementar el trabajo manual con el desarrollo psíquico y el intelecual con el ejercicio físico.

Conjunción armónica y reproductiva de organismos útiles.
Aumento progresivo de la población.

Puericultura y protección al adolescente sano, anormal y desvalido. Escuelas médicopsíquicas de orientación profesional.

Higiene y seguridad en el trabajo.

Máximo de horas de trabajo.

Alimentación sana y nutritiva, aportada por salario mínimo. Agua en condiciones de potabilidad.

Casa higiénica, urbes saneadas.

Alcoholismo, abusos venéreos, exceso del capital y de la herencia (sic.).

Bibliotecas y escuelas de adultos, círculos obreros, campos deportivos.

Matrimonios en condiciones de reproducción física.

Asclepio-Vol XLV-1-1993
Protección de la mujer en general, y en especial de la embarazada y de la que lacta.
Protección de la máquina

generadora del trabajo.

Asistencia en caso de interrupción trabajo.

Organismos imposibilitados para el trabajo. del mecanismo productor del
Seguro de Enfermedad, de accidentes, paro forzoso, etc.
Jubilación, pensiones, vejez, etc.

\section{NOTAS}

(1) Sobre los orígenes y el desarrollo de la Policia Médica, es clásico el trabajo de Ro SEN, G. (1953): «Cameralism and the Concept of Medical Police». Bulletin of the History of Medicine 27: 21-42. Existe una traducción castellana reciente en LESKY, E. (coord.) (1984): Medicina Social. Estudios y testimonios históricos, Madrid, Ministerio de Sanidad y Consumo. Colección Textos Clásicos Españoles de Salud Pública. Volumen complemen. tario. pp. 107-131. Otros textos de este autor sobre el tema pueden verse en RoSEN, $G$ (1985): De la policía médica a la Medicina social, México. Siglo XXI

(2) Así se especifica en los artículos 43.1 y 43.2 de la Constitución Española de 1978 Igualmente, en el artículo 41 , se estabiece que «los poderes públicos mantendrán un régimen público de Seguridad Social para todos los ciudadanos que garantice la asistencia y las prestaciones sociales suficientes ante situaciones de necesidad». Como es conocido, la última crisis económica y las políticas neoliberales puestas en marcha a partir de la déca-

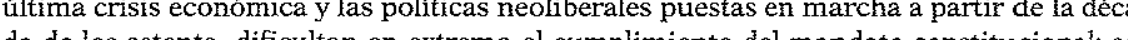
conal; sobre la evidente contadicción que supone el desarollo de unsistema sanitario publico en el marco de una política económica de corte liberal, hemos reflexionado en MAESTRO, A. y HUERTAS, R. (1992): La Salud y el Estado. Los servicios sanitarios públicos entre el bienestar y la crisis, Madrid, FIM.; MAESTRO, A. (1990): Situación actual y perspectivas del sistema sanitario público en España, Madrid, Conferencia publicada por la Escuela Nacional de Sanidad.; HUERTAS, R. (e.p): "El mito del "bienestar" y la política social». Utopias; HUERTAS, R. (e.p.): "El neoliberalismo, la política social y el sector salud» En ORTEGA, E. (coord): Las administraciones públicas, iprivatización o reforma? hospitalaria" El Médico.

(3) Sobre la creación de la Junta Suprema de Sanidad, desgajada del Consejo de Castilla, y su participación de las medidas tomadas bajo el reinado de Felipe V para hacer 
frente a la amenaza bubónica procedente de Francia, véase PESET, M. y J.L. (1972): Muerte en España (politica y sociedad entre la peste y el cólera), Madrid, Seminarios y Ediciones, pp. 30 y ss. Sobre las distintas posturas de absolutistas y liberales ante las medidas de sanidad publica en casos de enfermedades epidémicas, resulta de gran interés PESET, J.L. (1972): «Epidemias y sociedad en la España del Antiguo Régimen». Estudios de Historia Social, 4: 7-28.

(4) De acuerdo con Esteban Rodríguez Ocaña, entiendo por enfermedad social "aquella cuya causa tiene su origen en la propia organización de la comunidad y, más concretamente, puesto que así se desprende de su gestación histórica, de la desigualdad Social» [RoDRÍGuEZ OCAÑa, E. (1987): «El concepto social de enfermedad» En AlBaRRACín, A. (coord.): Historia de la Enfermedad, Madrid, Saned, pp. 341-349, p. 341. Aunque el término surge en el siglo XIX y se relaciona tradicionalmente con la aparición del proceso de mino surge en el siglo XIX y se relaciona tradicionalmente con la aparición del proceso de
industrialización y con una cultura eminentemente urbana, lo cierto es que la relación entre enfermedad y desigualdad social sigue constituyendo el núcleo central de la problemática salubrista, incluso a pesar de los cambios epidemiológicos acaecidos en la llamada sociedad post-industrial. Sobre este aspecto hemos reflexionado en HUERTAS, R. y MAESTRO, A. (1991): «Orígenes y contradicciones del concepto de Medicina Social». En HuERTAS, R. Y MAESTRO, A. (coords.): La ofensiva neoliberal y la sanidad publica, Madrid, FIM, pp. 39- 64. Véase, asimismo, BerıINGUeR, G. (1991): "Salud y desigualdades". En HUERTAS, $R$ y MAESTRO, A (coords): La ofensiva neoliberal y la sanidad publica, Madid, FIM, pp. 15-37.

(5) Como nos ha hecho notar Erwin H. Ackerknecht, aunque las relaciones entre mortalidad elevada y baja posición social habían sido claramente demostradas, no falta ron quienes, en una sobreestimación de la medicina invirtieron los kechos reales y afirmaron que la enfermedad era la causa de la pobreza y del pauperismo, lo que favoreció la conversión de la asistencia de los enfermos pobres en la clave de la cuestión social. Véase ACKERKNECHT, E.H. (1932): «Beiträge zur Geschichte der Medizinalreform von 1848. Armen-Krankenversorgung». Sudhoffs Archiv für Geschichte der Medizin, 25: 138-147. Existe una versi6n castellana: ACKERKNECHT, E. H. (1984): "Aporiaciones a la historia de la reforma médica de 1848. La asistencia a los enfermos pobres En Lesry, $\mathrm{E}$ (coord): Medicina nas 153-164. Relativamente reciente y de gran interés en el análisis de las relaciones entre el proceso salud-enfermedad y la estructura socioeconómica es el trabajo de EYER, J. y STERLLNG, P. (1977): «Strees-related mortality and social organization». Review of Radical political Economy, 1: $1-44$

(6) El reformismo médico ejerció, en este sentido, un importante papel de «mediación" entre los individuos y las nuevas realidades y necesidades sociales que, desconocidas hasta el momento, fueron surgiendo tras los distintos avatares del desarrollo capitalista. A. Labisch ha establecido, elevándolo a categoría de análisis, la existencia de un homo hygienicus habitante de una sociedad usaludabler, que ha tenido una definición explícita de clase al ser ideado y, en buena medida, ejecutado por los mismos sectores sociales que controlaron el proceso de modernización industrial que coincidió con la instauración del modo de producción capitalista. Resulta evidente que el desarrollo de un objetivo social claro como el de la salud hubiera resultado imposible sin la aceptación y reproducción por parte de los individuos de una necesaria serie de cambios comportamentales, para lo que fue preciso la tarea prolongada y persuasiva tanio de médicos como de otros agentes sociales. Sobre esta hipbtesis del papel «mediador» del médico y de los sistemas de salud, véase LABISCH, A. (1985): "Doctors, Workers and Scientific Cosmology of the In dustrial World. The Social Construction of "Health" and the "Homo Hygienicus" ». Journal of Contemporary History, 20:599-615. Inspirados en esta linea de pensamiento, son de tran interés para el caso español los trabajos de MOLERO, J (1989): Historia social de la tuberculosis en España (1889-1936), Tesis de doctorado, Universidad de Granada RODRíGUEZ OCANAA, E. (1992): «Paz, trabajo, higiene. Los enunciados acerca de la higiene industrial en la España del siglo XIX». En HUERTAS, R. y CAMPOS, R. (coords.): Medicina social y clase obrera en España (siglos XIX y XX), Madrid, FIM, pp. 383-406.; RoDRíGUEZ OCANA, E. Y MOLERo, J. (e.p.): «La cruzada por la salud. Las campañas sanitarias en el primer tercio del siglo XX en la construcción de la cultura de la salud». En MONTrEL, L. (co(1): La salud en el Estodo del Bienestar. Riesgos y beneficios de un nuevo valor. Madrid, UCM.

(7) Son conocidos los informes de Pulrdo, A. (1902): Sanidad Pública en España y ministerio social de las clases médicas, Madrid, Establecimiento tipográfico de Enrique Teodoro.; MARTiN SALAZAR, M. (1913): La sanidad en España, Madrid, Discursos leídos en la Real Academia de Medicina.; MuriLzo, F. (1918): La defensa social de la Salud Pública Madrid, Discursos leídos en la Real Academia de Medicina.

(8) Según expresa Murillo, «los tres conceptos que mejor pintan la situación sanitaria de un país son: la mortalidad general, la mortalidad infantil, y la mortalidad por enfermedades infecciosas $(\ldots)$. Ellas dan la medida de la salud pública, del grado de la acción sanitaria y el nivel de cultura popular y el bienestar económico que alcanzan las diferentes naciones" [MURILLo, F. (1918), p. 15].

(9) Martí SAlAZAR, M. (1913), p. 66

(10) Desde el punto de vista historiográfico, la mencionada Proposición de Ley ha suscitado cierto interés más que por sus contenidos científicos y/o sanitarios, porque supuso un motivo de enfrentamiento corporativo entre los médicos titulares y la administración sanitaria. Véase VILLACORTA, F. (1984): Profesionales y burócratas. Estado y poder corporativo en la España del siglo XX. 1890-1923, Madrid, Siglo XXI, pp. 487 y ss. También podrá verse HuERTAs, R. (e.p): «Fuerzas sociales y desarrollo de la salud pública en España. 1917-1923,. En II Encuentro Marcelino Pascua, 12 de junio de 1992. Madrid, Ministerio de Sanidad y Consumo.

(11) HAuSER, Ph. (1884): «El siglo XIX considerado desde el punto de vista médicosocial». Revista de España, 101: 202-224; 333-358.

(12) Hace especial referencia al aumento de los «padecimientos nerviosos» -en particular, la neurastenia-, y a las famosas plagas blancas: alcoholismo, sífilis y tuberculosis.

(13) HAUSER, Ph. (1884), p. 354

(14) Rosen, G. (1953): «Economic and Social Policy in the Development of Public Health. An Essay in interpretation». Joumal of the History of Medicine and Allied Sciences, 8: 406-430. La cita está sacada de una versiốn en castellano de esta trabajo publicado en LESKY, E. (coord.) (1984): Medicina Social. Estudios y testimonios históricos, Madrid, Ministerio de Sanidad y Consumo, pp. 53-80, p. 70.

(15) Ibid, p. 75 y ss.

(16) Tomado de HAUSER, Ph. (1884), p. 357 
(17) Laín, P. (1950): La historia clínica. Historia y teoría del relato patográfico, Madrid, CSIC

(18) Sobre este momento, crucial en la Historia de la Medicina, puede verse BaLDTY, P. (1976): The battle against bacteria, Cambridge; Cambridge University Press. Aunque con un enfoque biográfico, resultan útiles SrernBRuck, P. A. y THOM, A. (1982): Robert Koch (1843-1910), Leipzig, Johanm Ambrosius Barth.; BAGUENA, M.J. y PoRTeLA, E. (1988): Pasteur, Barcelona, Península.

(19) HAUSER, Ph. (1884), p. 356.

(20) Rosen, G. (1953): «Cameralism and the Concept of Medical Police». Bulletin of the History of Medicine, 27: 21-42. Existe una versión castellana en el ya citado LESKX, E. (coord.) (1984): Medicina Social. Estudios y testimonios históricos, Madrid, Ministerio de Sanidad y Consumo, pp. 107-131, p. 114. Veit Ludwing von Seckendorff (1626-1692) fue uno de los grandes teóricos del cameralismo alemán y pionero del concepto de Policía uno de los grandes teóricos del cameralismo alemán y pionero del concepto de Policía Médica, siendo su obra más destacada Der Deutsche
los principes), cuya primera edición apareció en 1665.

(21) Coincidiendo con la primera revolución obrera en Europa surge en Alemania un importante movimiento de Medizinische Reform que, capitaneado nada menos que por R. Virchow, subrayó que la medicina es una ciencia social y que sus relaciones con la política y con el tipo de organización socio-económica son intensas e incuestionables. Se inaugura así toda una linea de pensamiento que cristalizará en la Medicina Social como una disciplina científica cuyo objetivo fundamental será el de intervenir en la decisiones polí iduir que los poderes públicos asuman su «obligación» de proteger y asegurar la salud de los miembros de la sociedad. La bibliografía existente sobre R. Virchow es muy extensa e imposible de reproducir aquí. Una visión general de las aportaciones del famoso patólogo en el campo de la Medicina Social puede obtenerse en JACOB, W. (1965): "Aus dem sozialmedizinische Erbe Rudolf Virchow. Medizin als Wissenschaft vom Menschem». Janus, 52: 218-240 [versión castellana en LESKY, E. (coord.) (1984): Medicina Social. Estudios y testimonios históricos, Madrid, Ministerio de Sanidad y Consumo, pp. 165186].

(22) HAUSER, Ph. (1889) p. 357

(23) Sobre el importante papel que la lucha antituberculosa ha tenido en las propuestas y en el desarrollo de la administración sanitaria española, resultan imprescindibles los trabajos de MOLERo, J. (1987): Estudios médico-sociales sobre la tuberculosis en la España de la Restauración, Madrid, Ministerio de Sanidad y Consumo. Colección de Textos Clásicos españoles de la Salud Pública, n. ${ }^{\circ}$ 25.; Molero, J. y Rodríguez OCAÑa, E. (1988): «Tuberculosis y Previsión. Influencia de la enfermedad social modelo en el desarrollo de las ideas médicas españolas søbre el seguro de enfermedad». En VARELA, M., EgEA, M.A. y BEÁzouez, M.D. (eds.): Actas del VIII Congreso Nacional de Historia de la Medicina, Murcia, Vol. I. pp.

(24) Sobre la mencionada epidemia, existen estudios locales de gran interés. Véanse, BERNABEU, J. (coord.) (1991): La ciutat davant el contagi. Alacant i la Gripe de 1918-19, Valencia, Conselieria de Sanitat i Consum.; Rodríguez OCAÑA, E. (1991): «La Grip a Barcelona: un greu problema esporadic de salut pública. Epidemies de 1889-90 i 1918-19». En Cent anys de Salut Pública a Barcelona. Institut Municipal de la Salut, Barcelona, Ayuntamiento de Barcelona, pp. 131-156. También ECHEVERRI, B. (1990): La pandemia de Gripe de 1918-19 en España, Tesis doctoral inédita, Madrid, UCM
(25) Véase, a este respecto, PORRAS, M.I. (1992): «La epidemia de gripe de 1918-19 en prensa obreray. En HUERTAS, R y CAMPOS, R. (coords.): Medicina Social y clase obrera en España (siglos XIX y XX), Madrid, FIM, pp. 125-144.

(26) Sobre la crisis política de los últimos años de la Restauración, véase, entre otros, TuNón , M (1978): «Rasgos de la crisis estructural a partir de 1917». En La crisis del Estado Español. 1889-1936, Madrid, pp. 15-31. Asimismo, GARCíA DELGADO, J.L. (coord.) (1986): La crisis de la Restauración. España entre la primera guerra mundial y la II Repúbli$c a$, Madrid.

(27) Aunque de vida efímera - fundada en 1917 y desaparecida en 1920-, La Medicina Social Española fue una de las más influyentes publicaciones médicas de la época a constituirse en órgano de expresión de los Inspectores provinciales de Sanidad, de la Sociedad Española de Higiene y, hasta 1918, de los Inspectores de Sanidad exterior. Véase Ropricuez Ocun E (1987) pp. 42 y ss. Puede ser útil para hacerse una idea de la estrucCo de la misma, CARRERAS, A. (1972): dndir Española" (1917-1920)». Cuadernos de Historia de la Medicina Espa

(28) Véanse, a modo de ejemplo, LópEz COMAS (1920): "La sanidad nacional, para ser viable, debe apoyarse en la higiene». La Medicina Social, 5:278-282; FERRET, G. (1920): "La sanidad Nacional». La Medicina Social, 5:328-331.; FerNÁNDEZ AlcázAR, F. (1918):
"Garantía de la Salud Pública». La Medicina Social, 3:265-267.

(29) CoCA, F. (1918): «La necesidad de crear el Ministerio de Sanidad». La Medicina Ibera, n. ${ }^{\circ} 56$, p. LXIX

(30) Ibidem

(31) VALENZUELA, J. y RoDRiguez OCANA, E. (1988): «La política sanitaria ante la crisis pidémica de 1918. Reivindicación de un Ministerio de Sanidad». Actas del VIII Congreso Nacional de Historia de la Medicina, Murcia-Cartagena, diciembre de 1986. Murcia, vol. I. pp. 514-523, p. 523.

(32) COCA, F. (1918): «La necesidad de crear el Ministerio de Sanidad». La Medicina Ibera, 5: LXIX.

(33) «Lo que opina el Dr. Ramón y Cajal». La Medicina Ibera, 5: p 1

(34) «Lo que opina el Dr. D. Amalio Gimeno». La Medicina Ibera, 5: 22-23, p. 22.

(35) «Lo que opina el Dr. Murillo». La Medicina Ibera, 5: 46-47, p. 47.

(36) «Lo que opinan los Dres. Arana Quintana, de Sevilla; Wieden Viñarta, de Valencia; Muñoz Urra, de Talavera (Toledo); Linares Vivar, de Málaga; Díaz Rodríguez, de Málaga. La Medicina Ibera. 5: 154

(37) «Lo que opina el Dr. D. Jesús Centeno». La Medicina Ibera, 5: 98-99, p. 99. EI médico consultado no responde, en esta ocasión, a título personal sino como representante de las Asociaciones Sanitarias Regionales.

(38) «Lo que opina el Dr. M. Ruíz Maya». La Medicina lbera, 5: 153-154, p. 154

(39) «Lo que opina el Dr. Mezquita». La Medicina Ibera 5: 100.

(40) «Lo que opina el Dr. Chavás». La Medicina Ibera 5: 126-127, p. 126.

(41) Así se define la Medicina Social en un folleto de divulgación editado por el Instituto de Medicina Social, al que más tarde habré de referirme. Véase AGUADo, A. y Huertas, L. (1919) Cartilla popular de Medicina Social, Madrid, Instituto de Medicina Social.

(42) «Lo que opina el Dr. Forns». La Medicina Ibera 5: 70-71, p. 71. Curiosamente, Rafael Forns no envió sus comentarios a la redacción de la revista que se los pidió, publi- 
cando su "contestación» mediante la fórmula de una «Carta abierta» dirigida al Dr. Coca - director de La Medicina Ibera-y publicada en la Revista de Especialidades Médicas, 20 octubre-1918, cuyo texto fue, finalmente reproducido en La Medicina Ibera.

(43) Sobre esta institución, fundada en Madrid en 1918, véase ALVAREZ, R. (1988): «El Instituto de Medicina Social: primeros intentos de institucionalizar la eugenesia». As clepio 40 (1): 343-358. También RoDRíguez OCAÑA, E. (1987): La constitución de la Medicina Social como disciplina en España (1882-1923), Madrid, Ministerio de Sanidad y Consumo, pp. 36 y ss.

44) Problemas que englobaban «toda una serie de postemas sociales vergonzosas que se llaman PAUPERISMO, ANALFABETISMO, ALCOHOLISMO, SIFILIS y sus funestas consecuencias, la TUBERCULOSIS, la PROSTITUCION, la CRIMINALIDAD, la DEGENERACION, la LOCURA, que la ceguera política actual o no combate o lo hace con procedimientos arcaicos y bárbaros». [AGUADO, A. y HUERTA, L. (1919), p. 252.]

(45) Ibid, 260

(46) Ibid, p. 260.

(47) Entre otros, Sebastián Recasens, Gustavo Pittaluga, Gregorio Marañón, Manual Tolosa Latour, Antonio Piga, Bernabé Malo Poveda, etc.

(48) ALVAREZ, p. 356.

(49) Aguado, A. y HUerta, L. (1919): Cartilla popular de Medicina Sacial, Madrid, Publicaciones del Instituto de Medicina Social $n .^{\circ}{ }^{\circ}$, pp. 5-16. Una reciente edición de este texto ha sido publicada en Rodríguez OCAÑA, E. (1987), pp. 243-265. La cita textual coresponde a la p. 260 de esta última edición.

(50) Ibid, p. 247.

(51) Rico, F. (1922) «Política e higiene», El Siglo Médico, I: 74-76

(52) Rico, F. (1922) «Política e Higiene». El Siglo Médico, I: 553-554, p. 554

53) "Lo que opina el Dr. José Chava». La Medicina Ibera, n. ${ }^{\circ}$ 53: 126-127.

(54) No puede olvidarse la estrecha relación que en la época existía entre los parlamentarios y las «fuerzas vivas» de sus circunscripciones territoriales, por lo que no es de extrañar que salvo algunos diputados y senadores especialmente sensibilizados con el problema sanitario, los demás hicieran caso omiso de las propuestas presentadas. En otros lugares hemos reflexionado sobre las causas de la actual deuda sanitaria histórica, destacando el papel de la burguesía terrateniente e industrial de la España de la primera mitad del siglo XX, poco proclive a propiciar sistemas de protección socio-sanitaria. VéaSe HUERTAS, R. (1992): "La categoría "experiencia histórica» y la sanidad españolan. En HUERTAS, R y CAMPOS, R. (coords.): Medicina Social y clase obrera en Espana (siglos XIX.

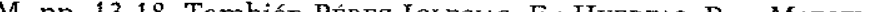
$X X)$, Madrid, HIM. pp. 13-18. También PÉREZ Iglesias, F; HuERT (5) .) «Politica económica y politica de salud». Papeles de la FIM

(55) Van-Baumberghen desempeñó una actividad parlamentaria muy intensa en los últimos años de la Restauración. Su condición de Inspector de trabajo le lievó a centrar sus propuestas en aspectos relacionados con el mundo laboral y, a través de él, con el sanitario; así, entre otras, "Proposición de Ley creandọ en España ocho Consejos Superiores del Trabajo y de la Sanidad» y «Proposición de Ley separando del Ministerio de la Go bernación los servicios afectos a la inspección general de sanidad para incorporalos a dos, 13 de abril de 1921.
(56) No he encontrado, en los debates parlamentarios subsiguientes a la publicación de la Proposición de Ley que nos ocupa, mención expresa, ni intervenciones de los diputados a favor o en contra de la misma.

(57) «Proposición de Ley del Sr. Van-Baumberghen, dictando las Bases para la creación del Ministerio de Sanidad Civil ». Diario de las Sesiones de Cortes. Congreso de los Diputados. (13 de abril de 1921), Apéndice 14 al número 37, p. 2. Los apéndices tienen numeración propia. Citado en lo sucesivo como VAN-BAUHBERGHEN (1921).

(58) Sobre la institucionalización de la eugenesia en España, véase Alvarez, $R$. (1985): «Introducción al estudio de la eugenesia española (1900-1936)». Quipu, 2: 95-122.

(59) Aunque el comienzo del proceso legislativo para instaurar en España el Seguro de Maternidad se inició en 1922, tras la ratificación del Convenio de Washington de 1919, éste no fue puesto en práctica hasta 1931, durante el primer bienio republicano. Véase RODRíGUeZ OCAÑA, E. (1990): «La asistencia colectiva en España, hasta 1936». En AlvaREZ. Junco, J. (coord.): Historia de la acción social pública en España. Beneficencia y previsión, Madrid, Ministerio de Trabajo y Seguridad Social, pp. 321-359, pp. 336 y ss.

(60) Ya F. Murillo, en su citado discurso «La defensa social de la Salud Pública», critica el taylorismo como un sistema especialmente nocivo para la salud de los trabajadores [MURLLLo, F. (1918), pp. 42 y ss]. En el intento de evitar la fatiga innecesaria del obrero sin menoscabar su rendimiento, jugó un papel importante la medicina a través de los institu tos y escuelas de orientación profesional. Sobre el particular, véase MEDINA, R.M. y RoDRfGUEZ OCANA, E. (1992): «La medicina en la organización científica del trabajo. El Instituto de Orientación Profesional (psicotécnico) de Barcelona (1917-1936)». En HUERTAS, R. y CAMPos, R. (coords.): Medicina Social y clase obrera en España (siglos XIX y XX), Madrid, FIM. tomo II, pp. 459-490.

(61) En particular, el alcoholismo es considerado como una de las grandes causas de absentismo laboral, con una serie de connotaciones morales de indudable trascendencia al considerarse una intoxicación "voluntaria» que podía llegar a afectar a un número importante de trabajadores. Sobre este aspecto, puede verse CAMPOS, R. y HuERTAS, R. (1991) «El alcoholismo como enfermedad social en la España de la Restauración». Dynamis, 11: 263-286.

(62) Sobre la historia de la previsión social en la época que nos ocupa, véase CUESTA, J. (1988): Hacia los seguros sociales obtigatorios. La crisis de la Restauración, Madrid, Ministerio de Trabajo y Seguridad Social.

63) Sobre la actitud y estrategias de la patronal, es de gran interés SIERRA, J. (1990) El obrero soñado. Ensayo sobre el paternalismo industrial (Asturias, 1860-1917), Madrid, Siglo XXI.

(64) RoDríguez OCAÑA, E. (1992): «Paz, trabajo, higiene. Los enunciados acerca de la higiene industrial en la España del siglo XIX). En HUERTAS, R. y CAMPOS, R. (coords.): $\mathrm{Me}$ dicina social y clase obrera en España (siglos XIX y XX), Madrid, FIM, t. П, pp. 383-406, dicina
p.394.

(65) VAN-BAUMBERGHEN (1921), p. 5

(66) Véase BEverIDge, W. (1944): Full Employment in Free Society, Londres. Puede encontrarse una traducción castellana reciente en las ediciones del Ministerio de Trabajo, Madrid, 1988.

(67) VAN-BAUMBERGHEN (1921), pp. 7-8. 
(68) Tales circunstancias se dieron, aunque con matizaciones diferentes, tanto en el momento de creación de la Seguridad Social a finales del siglo pasado, como tras la segunda Guerra Mundial con la aparición del llamado Estado del Bienestar. Véase PESET, J.L. (1978): «Capitalismo y medicina: ensayo sobre el nacimiento de la Seguridad Social». Estudios de Historia Social, 7: 185-216. También puede verse MAEsTro, A. y HUERTAS, R. (1992): La Salud y el Estado. Los servicios sanitarios públicos entre el bienestar y la crisis, Madrid, FIM.

(69) VAN-BAUMBERGhen (1921), p. 5.

(70) Se propone nacionalizar el capital extranjero, los aprovechamientos del subsuelo (minas), los de las corrientes de agua (energía hidráulica), los transportes, etc.

(71) Se propone gravar con impuestos sobre las causas posibles o ciertas de innecesario desgaste individual (imponiendo arbitrios extraordinarios sobre el consumo de bebidas alcohólicas, tabaco y sobre el juego) o sobre lo suntuario (venta de joyas, consumo de gasolina, cuotas sociales de Casinos, Círculos y sociedades recreativas, comodidades del servicio doméstico, etc.)

(72) VAN-BAUMBERGHEN (1921), p. 9.

(73) Otros seguros previstos en la Proposición de Ley son los de paro forzoso, senectud, anormales, ...

(74) Ibid, p. 10

(75) Ibidem.

(76) Véase Villacorta, F. (1984), pp. y ss.

(77) Sobre el desarrollo del Estado interventor, sus principios fundamentales y su gestación histórica, véase AsHFORD, D.E. (1986): The emergence of the Welfare States, Oxford. Basil Blackwell. Existe una traducción castellana editada por el Ministerio de Trabajo y Seguridad Social en 1989.

(78) Véase, a modo de ejemplo, Trrmuss, R. (1963): Essays on the Welfare State, Londres, Allen and Unwin. El problema, para este autor, se centra en el estudio de las instituciones (economía, etc.) y en el concepto de necesidad (aspectos éticos, de reparto, etc.)

(79) Una crítica a estas interpretaciones de la historia y de las dinámicas sociales puede encontrarse, centrando el análisis en el sistema de salud, en MaESTRo, A. y HUERTAS, R. (1992), pp. 12 y ss.

(80) Una visión general pero muy útil de la evolución administrativa de la sanidad española se encuentra en RODŔ̛GuEZ OCAÑA, R. (1992): «La estadística en la administración sanitaria española del siglo XX». En I Encuentro Marcelino Pascua, Madrid, Ministerio de Sanidad y Consumo, pp. 47-77.

(81) UGT (1932): Actas del XVII Congreso Ordinario, Madrid, p. 312. Los firmantes de la Ponencia fueron Cipriano Pastor, Júlio Bejarano, Sadi de Buen, Celiano Nartin, Isidro Cameno, Manuel Sierra y José Pérez.

(82) Mazuecos, A. (1982): «La política social socialista durante el primer bienio republicano: trabajo, previsión y sanidad». Estudios de Historia Social, 14: 135-146.

(83) Ello no fue obstáculo, sin embargo, para que Marcelino Pascua, al frente de la Dirección General de Sanidad, intentara una reforma sanitaria en profundidad. Véase BeRNABEU, J. (1992): «Marcelino Pascua desde la perspectiva histórica». En l Encuentro Marcelino Pascua, Madrid, Ministerio de Sanidad y Consumo, pp. 1115.

(84) «Lo que opina el Dr. Cortezo». La Medicina Ibera, 5 (n. $\left.{ }^{\circ} 49\right)$, p. 21.
(85) Para conocer tanto la alternancia de sus responsables como los cambios de deminación del Ministerio de Trabajo, resulta de gran utilidad SAMANIEgo, M. (1988): La unificación de los seguros sociales a debate. La Segunda República, Madrid, Ediciones de la Revista de Trabajo, pp. 50 y ss. Asimismo, Bernabeu, J., Zaragoza, P. y Perdiguero, E. (1992): «Medicina del trabajo en España. Aspectos normativos: de la Inspección a la Inspección Médica del Trabajo (1906-1935)", en HuERTAS, R. y CAMPOS, R. (coords.): Medicina social y clase obrera en España (siglos XIX y XX), Madrid, FIM, tomo I, pp. 295-320.

(86) Dicha subsecretaria contó con dos Direcciones Generales, una de Sanidad y otra de Asistencia y Previsión Social.

87) Dicho decreto tiene, a mi juicio, un gran interés histórico por ser el primer texto legislativo en el que las competencias de Sanidad - junto a las de Trabajo y Previsiónpasan a ocupar un espacio administrativo y político del más alto nivel, dentro del diseño de la política general española. Por este motivo me parece oportuno reproducirlo en su totalidad:

«A propuesta del presidente del Consejo de ministros y por acuerdo de éste,

Vengo a decretar lo siguiente:

Articulo $10^{\circ}$. Los servicios, cargos y deberes que dependen en la actualidad de la subsecretaria de Sanidad y Beneficencia, adscrita al ministerio de Gobernación, pasarán a depender, desde la publicación de este decreto, del ministerio de Trabajo, en el que en el próximo presupuesto se denominará: Ministerio de Trabajo, Sanidad y Previsión.

Artículo $20^{\circ}$. El ministerio de Trabajo, Sanidad y Previsión tendrá dos subsecretarías: la de Trabajo y Acción Social, y la de Sanidad y Previsión. La primera con dos direcciones generales, denominadas, respectivamente, de Trabajo y Acción Social. La segunda tendrá bajo su dependencia otras dos direcciones generales: la de Sanidad y la de Asistencia pública y Previsión Social.

Para el acoplamiento de los diferentes servicios dictará el ministro de Trabajo, Sanidad y Previsión las normas oportunas.

Articulo $33^{\circ}$. En tanto aprueben las Cortes los nuevos presupuestos, el Ministerio de Hacienda dictará o propondrá las medidas que estime pertinentes.

Hasta fin del corriente ejercicio, los créditos comprendidos en la subsección 2." de la sección $6{ }^{a}$ de los vigentes presupuestos generales del Estado continuarán figurando en dicha sección; pero las órdenes de pago serán expedidas por el ministro de Trabajo y Previsión.

De este decreto se dará cuenta a las Cortes.

Dado en Madrid a veinticinco de diciembre de mil novecientos treinta y tres.- NICETO ALCALA-ZAMORA y TORRES. - El presidente del Consejo de ministros, Alejandro Le rroux García.»

(88) Los debates parlamentarios sobre este tema están recogidos en el Diario de Sesiones de las Cortes de los días 20, 21, 22 y 23 de febrero de 1934. Los Anales del INP 26: 117-140, 1934, publicaron amplios fragmentos del debate, en especial los más directamente relacionados con la Sanidad y los Seguros Sociales. En lo sucesivo citaré por el mencionado número de la revista.

(89) Anales del INP (1934) 26: 117-140, p. 132

(90) Sobre el concepto de degeneración en la medicina positivista europea, puede consultarse HuERTAS, R. (1987): Locura y degeneración, Madrid, CSIC. Sobre la institucionalización de la reforma social en España, véase DE LA CALLE, D. (1989): La Comisión de 
Reformas Sociales. 1883-1903. Política social y conflicto de intereses en la España de la Restauración, Madrid, Ediciones de la Revista del Trabajo. También PaLACro, J.I. (1988), La institucionalización de la reforma social en España (1833-1924). La Comisión y el Instituto de Reformas sociales, Madrid, Ministerio de Trabajo.

(91) Anales del INP (1934) 26: 117-140, p. 132.

(92) lbid, p. 133.

(93) TIXIER, A. (1932): «El servicio médico y el seguro social». Anales del INP, 24: 761776, p. 765 .

(94) Anales del INP (1934) 26:117-140, p. 127.

(95) Ibid, p. 132.

(96) Ibidem.

(97) Ibid, p. 119.

(98) Sobre la incorporación de los medios y técnicas empleadas en las luchas contra las epidemias a las estrategias globales de control social es de gran interés Foucault, M. (1984) Vigilar y castigar. Nacimiento de la Prisión, Madrid, Siglo XXI. [original francés de 1975]. Sobre el particular he tenido oportunidad de reflexionar recientemente en HUERTAS, R, (e.p.): «Enfermedad y marginación». Gestae. Taller de Historia.

(99) Anales del INP (1934) 26:117-124, p. 132.

(100) UGT (1934), p. 3112. Resulta interesante constatar esta diferencia de criterios entre el PSOE y la UGT que, como puede apreciarse, no es ni mucho menos un fenómeno reciente. Véase PÉREz Ledesma, M. (1987): El obrero consciente. Dirigentes. partidos y sindicatos en la II Internacional, Madrid, Alianza. En especial, el capítulo 89, titulado "Partido y sindicato: unas relaciones no siempre fáciles», pp. 222-238.

(101) Recientemente, tanto Samanego, H. (1988), p. 52., como Velarde, J. (1990): El tercer viraje de la Seguridad Social en España, Madrid, Instituto de Estudios Económicos, p. 201, éste último citando a Mercedes Samaniego, han hecho referencia a esta intervención de M. Nelken sin detenerse a analizar el alcance de sus afirmaciones desde el punto de vista de la Política Sanitaria. Tal vez sea oportuno constatar, a propósito de este aspecto concreto, la utilidad del acercamiento interdisciplinar a unas mismas fuentes con el objeto de complementar enfoques y enriquecer, en definitiva, los resultados de la investigación histórica.

(102) Sobre los orígenes del mutualismo en España, véase MONFERo, F. (1988): Origenes y antecedentes de la Previsión Social, Madrid, Ediciones de la Revista de Trabajo, en particular el capítulo dedicado a «Beneficencia, Mutualismo y Previsión», pp. 65-117.

(103) Sobre los distintos «modelos» de sistema sanitario, es de interés el trabajo de TERRIS, M. (1978): "Three words systems of medical care: trends and prospectsi. American Joumal of Public Health, 68: 1125-1131. Existe una versión castellana en TERRIS, M. (1980): La revolución epidemiológica y la medicina social, México, Siglo XXI, pp. 177-196.

(104) Recientemente me he ocupado de esta cuestión en HuERTAS, R. (1992): «La concepción de los servicios sanitarios públicos en la II República». En HúerTas, R. y CAMPOS. R. (coords.): Medicina Social y clase obrera en España (siglos XIX y XX), Madrid, FIM, tomo II, pp. 555-579. 